\title{
Academic-Family Integration: How Do Men and Women in Distance Education and Residential Doctoral Programs Integrate Their Degree and Family?
}

\author{
Amanda Rockinson-Szapkiw \\ University of Memphis \\ Jessica Herring Watson \\ University of Central Arkansas
}

\begin{abstract}
Multivariate statistical analyses were used to determine if differences existed between how men and women enrolled in distance education and residential doctorate of education programs in the United States managed and negotiated their family and academic lives. Results provided evidence that distance education students $(n=106)$ reported having lower academic-family satisfaction and functioning, more interference between the academic and family domains, and more impermeable boundaries between the domains than their residential peers $(n=71)$. Moreover, women $(n=126)$ in comparison to men $(n=51)$ reported poorer academic-family balance and the desire to set more rigid boundaries between their academic and family domains.
\end{abstract}

Keywords: doctoral, distance education, gender issues, persistence, family integration

Rockinson-Szapkiw, A., \& Herring Watson, J. (2020). Academic-family integration: How do men and women in distance education and residential doctoral programs integrate their degree and family? Online Learning, 24(4), 112-130. https://doi.org/10.24059/olj.v24i4.2318

\section{Academic-Family Integration: How Do Men and Women in Distance Education and Residential Doctoral Programs Integrate Their Degree and Family?}

A growing number of doctoral students are choosing to seek their degrees in distance education programs (Allen \& Seaman, 2018), in which all or most coursework takes place using online systems. In 2018, 1.2 million postbaccalaureate students engaged in distance education, making up more than one third of the postbaccalaureate student population (National Center for Education Statistics [NCES], 2020). For many doctoral students, seeking degrees via distance programs is attractive as it is based on the expectation of flexibility and convenience (Berry \& Hughes, 2020; Bollinger \& Halupa, 2012). Because of the high level of flexibility and autonomy associated with distance education, a doctoral student can control when and where academic- 
related responsibilities are completed. This makes distance doctoral programs of particular interest to individuals, often women, who seek to integrate professional, academic, and family domains satisfyingly (Donnelly et al., 2016; Rockinson-Szapkiw, Sosin, \& Spaulding, 2018). Unfortunately, after entering a distance doctoral program, students, mainly women, report conflict and frustration related to managing and integrating their academic and non-academic domains (Rockinson-Szapkiw, Spaulding, \& Lunde, 2017). These reports are congruent with the research examining remote employees. Remote employees work more extended hours and have more workfamily conflict than their residential counterparts (Gajendran \& Harrison, 2007). When workers work from home, they experience work-family conflict since physical and mental boundaries between work and family are often blurred and difficult to manage (Kowalski \& Swanson, 2011).

The relationship between family and academic domains is complex for any doctoral student; however, distance doctoral students, like remote workers, may experience different complexities than their residential counterparts. Gender may also exacerbate the complex relationship between the two domains, as women often describe struggling to navigate the expectations of rigorous academic work while still feeling beholden to "traditional" social and cultural norms regarding family roles (Correll, 2001; Holley \& Gardner, 2012). Throughout theoretical and empirical literature, gender has been shown to significantly influence women's academic and career goals and decisions (Byars-Winston \& Rogers, 2018; Lent et al., 1994; Rockinson-Szapkiw, Holmes, \& Stephen, 2019).

The complex relationship between academic and family domains should be explored across populations (i.e., gender, program type) in light identifying, understanding, and managing the academic and family integration struggles that may inhibit success. Understanding the management and experience of academic-family integration, "the doctoral student's cognitive, behavior, psychological, and affective processes of integrating academic and family domains" (Rockinson-Szapkiw, 2019, p. 77), may be critical in identifying success factors and developing supports and policies that are instrumental in improving doctoral programs, especially distance programs where student enrollment, especially of women, is continually increasing and persistence is continually a problem (Jaggars et al., 2013; Kauffman, 2015; Rockinson-Szapkiw, Spaulding, \& Spaulding, 2016).

\section{The Role of Family in Doctoral Education}

Men and women are increasingly choosing to enter doctoral programs, with student enrollment in distance education programs increasing exponentially since 2012 (Hussar \& Baily, 2018; NCES, 2017; Seaman et al., 2018), and women outnumbering men in most programs (National Science Foundation [NSF], 2018). As doctoral students, both men and women, are generally over the age of 30, are married or in long-term, committed relationships and have children (NSF, 2019; Offerman, 2011).Over 50\% of doctoral students report familial roles and responsibilities as spouses, partners or, parents; almost all report responsibilities related to being sons or daughters and siblings (NSF, 2019; Smith, Maroney, Nelson, Abel, \& Abel, 2006). These roles and responsibilities are intimately connected to students' success, and, even more specifically, to their persistence in their programs (Athens, 2018; Hyun, Quinn, Madon, \& Lustig, 2006; Mirick \& Wladkowski, 2020; Rockinson-Szapkiw et al., 2019). The importance of family in the success of doctoral students in residential programs is well documented (Martinez, Ordu, Sala, \& McFarlane, 2013; Schmidt \& Hansson, 2018). Literature on distance doctoral students is beginning to emerge, demonstrating the same; family is salient to success and persistence (Rockinson-Szapkiw et al., 2019). 
When seeking a doctoral degree, residential students have reported a breakdown in familial communication (Bergen \& Bergen, 1978; Giles, 1983; Jairam \& Kahl, 2012; Williams, 1977) and misalignment of values (Scheinkman, 1988). In her organizational model explaining the influence of the doctoral degree on the marriages of residential students, Scheinkman (1988) proposed that as one spouse pursues a doctoral degree, a disparity in interests, values, and life goals can result (Scheinkman, 1988). For example, doctoral students may believe that the degree is valuable, and everything should be sacrificed for it. The non-degree seeking spouse is not likely to hold the same value of the degree, becoming frustrated with the degree-seeking spouse who may value academic responsibilities over family responsibilities (Scheinkman, 1988). A degree-seeking individual's spouse and family may even view the doctoral program as "stealing" from the family (Gardner, 2009; Gold, 2006), and resentment may develop for the degree and degree-seeker (Jairam \& Kahl, 2012; Smith et al., 2006). Researchers have concluded, via qualitative research, that misalignment in the value of the degree among family members as well as other conflicts that occur between the family and academic domains can be a "destructive force" (Smith et al., 2006, p. 23). Guilt, shame, and anxiety over not being able to manage time for family, time for self, and academic expectations are often felt by the doctoral student (Brown \& Watson, 2010; Lipschutz, 1993; Smith et al., 2006). Schmidt and Hansson's (2018) literature review demonstrated that family and familial relationships are often a significant source of stress for doctoral students. Insomnia, somatic symptoms, depression, poor well-being, inhibited concentration, and reduced immune functioning are additional documented consequences for a doctoral student experiencing a lack of familial support or conflict between the academic and family domains (Cushway, 1992; Wasburn-Moses, 2008; Zahniser et al., 2017). Unfortunately, sustained stress and other consequences are reasons that many doctoral students change their aspirations, quit their programs, or divorce (Mason et al., 2009; Mirick \& Wladkowski, 2020; Rockinson-Szapkiw et al., 2017). On the other hand, family support and a sense of balance between the academic and family domains are associated with residential doctoral students' well-being and degree completion (Hoskins \& Goldberg, 2005; Lott et al., 2009; Martinez et al., 2013; Ülkü-Steiner, Kurtz-Costes, \& Kinlaw, 2000). For example, conducting a regression analysis on self-report data from over 200 professional psychology graduate students, Tompkins et al. (2016) found that family support significantly predicted both life and program satisfaction. In conducting a qualitative study with five full-time doctoral students enrolled in PhD education programs, Martinez et al. (2013) found that students who reported purposefully managing their time and responsibilities related to their degree and families often expressed a more satisfying balance between non-academic and academic domains.

Similarly, limited research on distance doctoral students supports the essential role family plays in doctoral students' success and persistence. Rockinson-Szapkiw et al. (2016), examining the self-report data of distance doctoral student, found that family support significantly predicted persistence into doctoral candidacy. In a grounded theory study examining persistence in online EdD candidates who grew up in poverty, Rockinson-Szapkiw, Spaulding, Swezey, and Wicks (2014) posited that students' persistence is partially attributable to "the degree to which the candidate's sense of connectedness with family members is met while pursuing the doctorate" that "not only includes the maintaining of familial relationships and relatedness (a sense of belonging and care) but also includes the 'fit' between the degree and family values" (Rockinson-Szapkiw, Spaulding, Swezey, \& Wicks, 2014, p. 196). Breitenbach, Bernstein, Ayars, and Konecny (2019) similarly found that when distance doctoral students' families valued the degree, the doctoral student felt supported. Conversely, when doctoral students' families did not value the degree or 
think the pursuit of the degree was a responsible use of money, the student and family experienced stress.

Despite decades of research, especially within residential doctoral programs, noting that the family and academic domain interaction is complex and is vital to student success, limited research has sought to understand how students manage their academic and family domains satisfyingly when pursuing and persisting in a doctoral program (Rockinson-Szapkiw, 2019).

\section{Review of Relevant Literature}

The term family in this study is consistent with the theoretical research and refers to the individuals with whom doctoral students live and have close and social relations. Family was inclusive of children living in the home or as dependents at college, spouses or partners, and parents living in the home. Research is only beginning to emerge on the interaction between the academic and family domains of doctoral students; therefore, this research draws upon and applies work-family research and the constructs of work-family balance, work-family boundaries, and work-family borders. This body of research encompasses the interference and harmony that occurs between work and family domains. Proponents of the work-family (WF) theory (Ashforth, Kreiner, \& Fugate, 2000; Nippert-Eng, 1996; Clark, 2000) have posited that individuals make personal decisions about how to construct, negotiate, and hold boundaries (e.g., "lines of demarcation") or borders (e.g., "mental fences") between work and family.

Management of boundaries (also called borders in some theoretical work) shapes how family and work responsibilities are managed and how relationships are formed. Integration and segmentation represent the two ends of a continuum that individuals use to integrate work and family (Brue, 2019; Clark, 2000; Nippert-Eng, 1996). The degree of interaction, including physical, temporal, and psychological dimensions, between family and work depends upon the boundaries or borders that individuals set to create a desired work-family balance, "satisfaction and good functioning at home and work, with a minimum role conflict" (Clark, 2000, p. 751). Nippert-Eng (1996) and Kreiner et al. (2009) explained that some individuals prefer to be integrators, while others prefer to be segmentors. Clark (2000) and Ashford et al. (2000) used the concepts of flexibility (i.e., malleability) and permeability (i.e., level of interaction between domains) to characterize integration and segmentation. For integrators, the domains of work and family are highly flexible and permeable. For segmentors, domains of work and family are kept separate and are inflexible and impermeable (Ashforth et al., 2000; Clark, 2000; Methot \& LePine, 2016). Applying WF theory, Rockinson-Szapkiw developed the term academic-family boundaries, which is "described as the flexibility, and permeability one uses to negotiate the overlapping boundaries (e.g., time, space, people) between academia and family to achieve satisfaction and maximize functioning" (Rockinson-Szapkiw, 2019, p. 86). Like WF theory, she purported that boundaries can influence balance, more specifically, academic-family balance, which is the doctoral student's "satisfaction with the interaction between and assessment of their functioning within the realms of both academia and family" (Rockinson-Szapkiw, 2019, p. 84). This construct, like WF balance (Friedman \& Greenhaus, 2000) includes the assessment and satisfaction of where time and attention is focused as well as the ability to meet needs of individuals within both the family and academic domains (Friedman \& Greenhaus, 2000) Academic-family balance also includes ideas drawn from doctoral persistence literature, including the fit a doctoral student 
perceives between the degree and the satisfying connection the student can have with the family while maintaining an identity as a scholar or student.

Research on academic-family boundaries is almost nonexistent, and the benefits of segmentation versus integration on functioning and satisfaction (i.e., balance) in WF literature is mixed. While some researchers advocate the benefits of integration to ameliorate the conflict and dissatisfaction with family and work domains (Olson-Buchannan \& Boswell, 2006), others have touted that segmentation reduces family-work conflict and dissatisfaction (Ashforth et al., 2000; Powell \& Greenhaus, 2010). Paustin- Uderahl et al. (2016) argued that high levels of permeability and interaction between the family and work could allow for the transferability of resources, which can be helpful. On the other hand, this can be hurtful, as Xu et al. (2018) found that high levels of permeability and integration of work and family often require undesirable sacrifices in both domains. Yet, other theorists have noted that the degree of segmentation or integration, and the benefits or drawbacks, is complex and dependent upon a variety of factors (e.g., time management, the match between work and family domains, type of work, work environment, work policies, and culture) (Ashforth et al., 2000; Clark, 2000; Nippert-Eng, 1996; Methot \& LePine, 2016).

Moreover, satisfaction and functioning may be maximized when a match between personal preference and work environment is maximized rather than the "mere act of integrating or segmenting" (Kossek et al., 2012, p. 124). Methot and LePine (2016) further extended the discussion of segmenting as a complex and nuanced decision-making practice by arguing that segmentation is split into distinct dimensions. Individuals may express different preferences for protecting these two domains, rather than strictly separating them from one another. For example, an individual might exert effort to protect the work domain from the interference of the family domain while simultaneously allowing work interference in the family domain. Berry and Hughes (2020) noted that the already complex decision-making process of segmenting is further complicated by nearly ubiquitous access to both work and home domains through mobile devices. Consistent with WF theory, Rockinson-Szapkiw, Sosin, and Spaulding (2018), via a phenomenological study of women in the distance doctoral programs, found that the concepts of segmentation and integration were salient in how women chose to integrate their doctoral degrees and families. They noted that the degree of segmentation or integration is a personal choice and influences personal satisfaction with the degree and family domains. WF researchers have noted that continued investigation to understand the complex interaction between boundary setting and its effects on life, family, and work performance is needed (Brue, 2019; Methot \& LePine, 2016). Brue (2019) noted that this area of research remains underdeveloped, and the area of academicfamily research is even more underdeveloped (Rockinson-Szapkiw, 2019; Sallee, 2016).

\section{The Role of Interference and Environment}

Differences exist regarding work-family experiences for traditional, telecommuting (i.e., working from home 1 to 3 days a week), and remote (i.e., working solely from home) workers. Considering parallels between remote work and distance education, similar differences in academic-family experience may exist between residential and distance doctoral students. Traditional work-family theory (e.g., Ashforth, et al., 2000; Clark, 2000) assumes that the family and work domains are physically separate; however, for remote workers, like distance doctoral students, work is usually physically embedded in the family domain. Consequently, in a qualitative study of remote workers, Eddlestone and Mulki (2017) demonstrated that work often physically and psychologically intrudes on the family time. The lack of separation decreased worker's ability 
to disengage from work in the home, which was harmful to the family, especially if the worker was a woman.

Moreover, remote workers frequently experienced unexpected invasions or unintended interruptions, often referred to as interference in the WF literature, in work related to the family domain. The lack of physical boundaries increased the interaction or integration between the work and family domains. Consequently, remote workers reported conflict between the domains, which increased stress. Other researchers have documented similar findings, noting that work-family conflict is more prevalent for remote workers compared to those who have a traditional work environment since boundaries between work and family are often blurred and difficult to manage when the two are not physically separate (Kowalski \& Swanson, 2011). A remote worker's boundary preferences (i.e., segmentation vs. integration) can further influence the remote worker's work-family conflict and level of stress, especially when there is a misalignment between the worker's ability to manage each domain in a preferred way due to lack of physical boundaries (Kreiner, 2006). Distance doctoral students may have similar experiences between their academic and family domains as, like remote workers, the physical boundaries (e.g., students desk is the kitchen table, or a desk is set up in a bedroom) between academic and family are likely to be blurred, no matter doctoral students' preferences for segmenting or integrating. Also, academicfamily interferences, unexpected invasions or unintended interruptions that occur between the academic and family domains (e.g., kids doing karaoke while the student is taking an online test; a sick child results in an assignment being submitted late; child's soccer game rescheduled due to rain), may be experienced differently by distance and residential students, just like the remote worker reported more frequent interferences when working remotely compared to working in an office away from home.

\section{The Role of Gender}

Gender differences have also been documented within the work-family literature as well as within the doctoral education literature. Family and spousal support for working women decreases stress and minimizes work-family conflict (Paustain-Uderdahl et al., 2016). Conversely, familial and spousal demands and the inability to manage home and work responsibilities can be detrimental and increase work-family conflict for both men and women (Paustain-Uderdahl et al., 2016). Unfortunately, gender inequality within the home and workplace is evident, with more familial demands often being placed on women at home and more gender barriers being in place at work. Therefore, women often experience less satisfaction and poorer functioning within both domains. Moreover, these social and cultural factors (e.g., gender norms, family expectations) can mediate their choices and goals (Lent et al., 1994), resulting in a woman not pursuing a promotion at work or leaving the family. For example, if a woman feels very little family support for pursuing a career, she might then express lower expectations regarding the feasibility of pursuing that career.

Researchers have also suggested that gender may also influence how doctoral students handle familial issues (Easterly \& Ricard, 2011; Lynch, 2008; Jones et al., 2013). Gender discrimination remains prevalent in higher education programs (Easterly \& Ricard, 2011), and women in residential, doctoral programs often choose to hide familial issues out of fear of stigma and decreased power (Lynch, 2008; Jones et al., 2013). Women, more than men, experience barriers to scholarly pursuits due to traditional views of women as primary providers of childcare, emotional support, and household chores (Correll, 2001; Mason at al., 2009). Normative gender roles tend to associate women with the family and men with work and academics (Hochschild \& Machung, 2012; Reskin \& Bielby, 2005). For example, researchers in one study found that while 
the social supporters of men tended to encourage the family to make sacrifices for the doctoral degree, social supporters advised women to quit their programs to focus on the family (Carter, Blumenstein, \& Cook, 2013). External pressure and negative repercussions associated with gender roles can leave women in doctoral programs feeling conflict and shame (Lynch, 2008). Repeatedly in interviews of both distance and residential doctoral students, women have purported that their roles as wife, mother, and daughter, in part, result in difficulties in doctoral programs (Stimpson \& Filer, 2011; Rockinson-Szapkiw et al., 2017). The shouldering of additional tasks, traditionally termed "women's work" (e.g., childcare, housework), causes physical and psychological stress (Ray \& Miller, 1994; Smith et al., 2006). While the spouses of some doctoral degree-seeking women are willing to take on more non-traditional or supportive roles, many women report that their negotiated roles and division of labor remain mostly traditional (Lyonette et al., 2015; Rockinson-Szapkiw, et al., 2018; Rockinson-Szapkiw, Spaulding, \& Knight, 2015). Given this, men and women may choose to integrate the family and doctoral degrees differently.

\section{Purpose}

While previous literature has established that family affects students' persistence, wellbeing, family life, and degree satisfaction (Brus, 2006; Mason, Goulden, \& Frasch, 2009; Offstein, Larson, McNeill, \& Mwale, 2004; Rockinson-Szapkiw, Spaulding, \& Lunde, 2016; Stimpson \& Filer, 2011), little is known about doctoral students' academic-family integration. Research that has been done on doctoral education and the role of the family has been primarily qualitative, focusing either specifically on residential or distance students. How residential and distance doctoral students, as well as men and women, differ, if at all, in setting up boundaries and managing interference between the two domains to maximize their satisfaction and functioning is unknown. Exploration of type of program (i.e., residential vs. distance) differences is warranted as work-family literature has documented the differences in work-family experiences across residential and remote employees (Gajendran \& Harrison, 2007). Researchers have also clearly documented that a match between personal preference for work-family integration and environment is central to maximizing satisfaction and functioning in both the work and family domains (Kossek et al., 2012). Findings may hold in the academic environment as well. Domain integration between residential and distance students may differ, and personal preference and type of environment in which the degree is pursued (e.g., residential degree, distance degree) may influence a doctoral student's life quality, success with relationships, and completion of the degree. Moreover, gender cannot be ignored as ongoing research has documented that women, especially mothers, face more challenge than men in combining family life and doctoral education due to the culture of academia (Rockinson-Szapkiw, Spaulding, \& Lunde, 2017), gendered expectations within the home and higher education institution (Correll, 2001; Lent et al., 1994; Reskin \& Bielby, 2005; Sallee, 2016; Wood \& Eagly, 2010), and insufficient family-friendly supports and policies (Lynch, 2000; Springer et al., 2009).

Understanding how men and women in both types of doctoral degree programs experience the academic-family integration phenomenon is foundational to helping students maximize functioning and satisfaction in both domains and providing the support and policy development needed to promote success, including achievement and persistence. Therefore, in this research study, we sought to investigate how men and women across distance and residential doctoral programs differed in integrating their academic and family domains. The research questions guiding this study were twofold: (a) To what extent, if any, do residential and distance doctoral students differ in their academic-family balance, boundaries, and interference? (b) To what extent, 
if any, do men and women in doctoral programs differ in their academic-family balance, boundaries, and interference?

\section{Methods}

\section{Design, Participants, Setting, and Procedures}

A causal-comparative research design was employed to investigate the research questions. Multivariate analyses of variances (MANOVAs) were used to analyze the data followed by analyses of variances (ANOVAs) for each dependent variable. The effect sizes were calculated using partial eta squared, and interpretation was based on Cohen's (1977) conventions of .01 for a small effect, .06 for a moderate effect, and .14 for a large effect.

A convenience sample of 177 doctoral students was used. The volunteer rate was $67 \%$. After receiving institutional review board approval, we elicited participation from doctoral students enrolled in $\mathrm{EdD}$ and $\mathrm{PhD}$ programs at four universities, both private and public, in the United States.

Participants from four institutions were used due to convenience and access. Three of the institutions had both distance and residential programs; one institution only had a distance doctorate program. All programs had a similar curriculum, required between 54 and 60 credit hours, and were considered professional doctorate programs. The distance education programs could be categorized as "exclusively distance education" and "some, but not all distance education" (Allen \& Seaman, 2017). In all distance programs, at least $80 \%$ of the doctoral degree was completed online; residential programs required on-campus courses exclusively.

Students were invited to participate in the study via an email; emails were sent via program directors and chairs to students to provide an invitation. The invitation explained the purpose of the study and set forth criteria for study participants, including (a) being currently enrolled in a residential or distance doctorate of education program and (b) having a family system that was perceived to influence doctoral degree (e.g., "Survey question: Please respond yes or no. I am part of a family system [e.g., married, single parent, caregiver for a parent, living with a partner] and have family living in my home full or part time that influences my doctoral degree work. And, please describe your family [optional fill in the blank]"). Over half of the participants had children under the age of 18 living in their homes $(n=100,56.5 \%)$. Twenty-four $(13.5 \%)$ participants reported that they cared full or part-time for aging parents, with thirteen $(7.3 \%)$ reporting that their parents lived in their home full time. The majority of participants were married $(n=155,87.6 \%)$, defining their family as "a spouse;" "a partner;" "spouse and children under 18 living in the home;" "spouse and child(ren) in college;" "children in the home and at college and a spouse;" "partner and kids in the home;" "spouse and in-laws in the home;" and "spouse, children, and parents in the home." Twenty-two participants reported being divorced or single and defined their family as "parents and children;" "small children in the home;" "children in college and at home;" and "adult and small children." These individuals had either parents or children under the age of 18 living in their homes.

Students in both the residential and distance programs were at various points in their doctoral programs: year one of coursework $(n=41,23.2 \%)$, year two of coursework $(n=44$, $24.9 \%)$, working on the dissertation proposal $(n=42,23.7 \%)$, and working on their dissertation research $(n=50,28.2 \%)$. All students identified as cisgender men or women (e.g., survey 
question, "Please specify the gender in which you identify."); no participant selected "other" or "prefer not to disclose" on the survey question. Therefore, women $(n=126)$ represented $71.2 \%$ of the sample, whereas men $(n=51)$ represented $28.8 \%$. A chi-square test of independence was conducted between gender and program type, and results demonstrated that there was not a statistically significant association between gender and program type, $p=.170$. Women out numbered men in both the residential and distance education programs. This sample of more women is consistent with the relatively large number of women enrolled in doctoral programs in education and online (NSF, 2018). It is also important to note that the analyses for this study consisted of two separate MANOVAs instead of a factorial MANOVA as the number of men within each program type was approximately $30 \%$, making the group size small (e.g., $n=18$ in the residential group) and inadequate for a $2 \times 2$ MANOVA. Future studies should consider examining the interaction effect between program type and gender.

In other words, in both the residential and distance programs, approximately $70 \%$ were women. The ethnic breakdown was: White $(n=128,72.3 \%)$, African American $(n=18,10.2 \%)$, Asian $(n=8,4.5 \%)$, Hispanic $(n=20,11.3 \%)$, and other $(n=3,1.7 \%)$. The majority of the participants ranged in age 30 to $49(n=121,68.4 \%)$.

\section{Instrumentation}

Potential participants used the link embedded in the email invitation to access the online survey, consisting of the Doctoral Academic-Family Integration Inventory (Rockinson-Szapkiw, 2019), doctoral experience questions, and demographic questions. The Doctoral Academic-Family Integration Inventory (DAFFII; Rockinson-Szapkiw, 2019), which served as the measure for the dependent variables, is a 22-item Likert-type scale measure. The inventory measures doctoral students' academic- family balance, boundary-setting, and interference. Participants responded to items using five-point Likert type scales (e.g., $1=$ strongly disagree to $5=$ strongly agree or $1=$ strongly dissatisfied to $5=$ strongly satisfied). Example questions from the measure include, "I share unpleasant things that happen in my doctoral program with family," and "The degree of relatedness (connectedness) maintained with my family while pursuing my doctoral degree." The Academic-Family Balance scale consists of 12 items and scores range from 1 to 5 . Higher scores indicate a higher level of satisfaction and functioning in balancing academic and family domains. The Academic-Family Boundary Setting scale consists of five items, with possible averaged scores ranging from 1 to 5 . Lower scores on the scale indicate that doctoral students are more likely to segment their degree and their family domains. Whereas, higher scores indicate that doctoral students are more likely to integrate their degree and family. Finally, the average score on the Academic-Family Interference also ranges from 1 to 5 . The higher the score, the more the family and academic domains distract from one another. Rockinson-Szapkiw (2019) reported that a primary component analysis and confirmatory factor analysis demonstrated that the scale is a valid measure for a doctoral student. Reportedly, the subscales have strong internal reliability with a Cronbach's alpha coefficients ranging between .85 and .95 . Cronbach's alpha for the current study for the three subscales ranged between .90 and .95 . 


\section{Results}

Table 1 provides the descriptive statistics disaggregated by gender and program type (distance, residential) for the 177 participants.

Table 1

Descriptive statistics $(N=177)$

\begin{tabular}{lllllllll}
\hline Variable & \multicolumn{2}{l}{$\begin{array}{l}\text { Men } \\
(\boldsymbol{n}=\mathbf{5 1})\end{array}$} & \multicolumn{2}{l}{$\begin{array}{l}\text { Women } \\
(\boldsymbol{n}=\mathbf{1 2 6})\end{array}$} & \multicolumn{2}{l}{$\begin{array}{l}\text { Distance } \\
(\boldsymbol{n}=\mathbf{1 0 6})\end{array}$} & \multicolumn{2}{l}{$\begin{array}{l}\text { Residential } \\
(\boldsymbol{n}=\mathbf{7 1})\end{array}$} \\
\hline & $M$ & $S D$ & $M$ & $S D$ & $M$ & $S D$ & $M$ & $S D$ \\
\hline Academic-Family Balance & 2.60 & .80 & 2.12 & .77 & 1.92 & .64 & 2.77 & .76 \\
Academic-Family Boundary Setting & 2.00 & .96 & 1.52 & .59 & 1.54 & .67 & 1.84 & .82 \\
Academic-Family Interference & 3.58 & 1.09 & 3.41 & 1.06 & 3.26 & 1.13 & 3.76 & .90 \\
\hline
\end{tabular}

Table 2 displays the Pearson $r$ intercorrelations between the dependent variables, the elements of academic-family integration. There were small, positive, and negative correlations between each set of variables. Correlation analyses demonstrated that, in general, doctoral students who integrated their academic and family domains had higher satisfaction and functioning. However, the more students integrated, the more interference they experienced. The more interference the doctoral student perceived between the domains, the less academic-family balance was experienced. The associations among the variables also provide the impetus for performing multivariate analyses of variance (MANOVAs).

Table 2

Correlation Matrix

\begin{tabular}{lcc}
\hline & AF Balance & AF Boundary Setting \\
\hline AF Balance & - & $.37^{*}$ \\
AF Interference & $-.33^{*}$ & $.45^{*}$ \\
\hline Note ${ }^{*}<<.001$ & &
\end{tabular}

Note. ${ }^{*} p<.001$

Before conducting the parametric analyses, assumption testing was conducted. No major violations for the following assumptions were found in the following areas, univariate normality, multivariate normality, and extreme outliers, multicollinearity, and singularity, linearity, homogeneity of variance, or homogeneity of variance-covariance. Therefore, multivariate analyses of variance (MANOVAs) were used. The first one-way MANOVA was conducted to determine the effect of program type on the three elements of academic-family integration. A significant difference was found between doctoral students completing their degrees at a distance versus in residence on the combination of the three dependent measures, Wilks' $\Lambda=22.15, F(3,173)=7.36, p<.001$. The effect size was large, partial $\eta 2=.28$, indicating that residential and distance students varied largely in how they approached family integration. Separate analyses of variances (ANOVAs) for each dependent variable were also conducted. Bonferroni's adjustment $(.05 / 3=.02)$ was used to control for family-wise error; the alpha value used to determine if the ANOVAs were significant was .02 instead of .05. Results of ANOVAs demonstrated that students in 
residential and distance programs significantly differed on all three variables (see Table 3). Effect sizes were small to moderate.

A second one-way MANOVA was then conducted to determine the effect of gender on the three elements of academic-family integration. Significant differences were found between men and women on the combination of the three dependent measures, Wilks' $\Lambda=.89, F(3,173)=7.36, p<.001$. The effect size was moderate, partial $\eta 2=.11$. Separate analyses of variances (ANOVAs), using Bonferroni's adjustment to determine significance, revealed that men and women significantly differed in their academic-family balance and boundary setting (see Table 3). Their perceptions of interference between the academic and family domains did not significantly differ. Effect sizes were moderate to large. These results are discussed in further detail in the discussion section.

Table 3

Separate ANOVA Results

\begin{tabular}{lll}
\hline Variable & Results for Program Type & Results for Gender \\
\hline Academic-Family & $\begin{array}{l}F(1,176)=64.97, p>.001, \text { partial eta } \\
\text { Balance }\end{array}$ & $\begin{array}{l}F(1,176)=13.92, p>.001, \text { partial } \\
\text { eta squared }=.07, \text { power }=.96^{*}\end{array}$ \\
Academic-Family & $F(1,176)=7.48, p=.007$, partial eta & $F(1,176)=15.95, p>.001$, partial \\
Boundary Setting & squared $=.04$, power $=.88^{*}$ & eta squared $=.08$, power $=.98^{*}$ \\
Academic-Family & $F(1,176)=9.79, p=.002$, partial eta & $F(1,176)=.91, p=.34$, partial eta \\
Interference & squared $=.05$, power $=.78^{*}$ & squared $=.005$, power $=.51$ \\
\hline
\end{tabular}

Note. *Results were significant

\section{Discussion}

Results demonstrated that doctoral students attending residential and distance programs differ in their academic-family integration. Distance education students reported significantly lower academic-family balance than their residential peers. That is, distance education students perceived lower satisfaction and functioning in integrating their academic and family domains than their residential peers. Like remote workers, the boundaries between academic and family domains may be blurred as there is no physical space separating the two domains (Berry \& Hughes, 2020; Kowalski \& Swanson, 2011). Distance education students do not travel to a campus for classes and may not have a library to which they can go to study. Consequentially, coursework and studying may take place at home. With no physical location or time designated for doctoral work, the family and the student may be uncertain how to navigate the student's need for time and space to study, resulting in stress and conflict (Gajendran \& Harrison, 2007).

In an attempt to clarify and define boundaries between domains (i.e., address the blur of boundaries), distance education students may attempt to establish impermeable and inflexible boundaries between their degrees and their families; that is, they may choose to be segmentors. This may explain why distance education students in this study reported significantly lower scores on the boundary scale than their residential counterparts, a finding similar to results in other 
studies. For, some of the participants in Rockinson-Szapkiw et al.'s (2017) study reported isolating the academic and familial domains (e.g., being a mom during the day participating in all children's events and being a student working on doctoral work when children are sleeping) to finish the distance doctoral degree successfully. Unfortunately, in segmenting as an attempt to clarify the blurred boundaries between the domains, students may ignore their preferences for academicfamily integration, resulting in poor functioning and satisfaction (Kossek et al., 2012).

The results demonstrating that the residential students had slightly higher scores on the interference scale (i.e., residential students perceive more interference than distance education counterparts) may at first seem counterintuitive. However, the flexible structure of the distance program, which has no scheduled class time, may enable distance education students more flexibility to accommodate the needs of the family (Berry \& Hughes, 2020). For example, a distance education student may rearrange his or her scheduled study time to take a sick child to a doctor. While this is inconvenient, it is doable. Whereas, a residential student may need to miss a class to take a sick child to a doctor. The residential student cannot rearrange the class schedule to care for a sick child. The distance education student may not perceive the unexpected event of a sick child as disruptive to his or her doctoral studies in the same manner as a residential student.

Gender differences were also examined in this study. Findings demonstrated that women in comparison to men tended to segment their family and academic domains. That is, women tended to create physical, emotional, and cognitive barriers between their family and school. As normative gender roles tend to associate men with academics and women with family, it was not surprising that the study findings cohere with previous findings that women feel the need to hide or segment the two domains (Hochschild \& Machung, 2012; Reskin \& Bielby, 2005). Given the fact that women are often expected to carry more material (Hochschild \& Machung, 2012) and emotional work (Erikson, 2005), women may experience social pressure to give up their doctoral studies, especially when these studies are seen as interfering with familial responsibilities (Carter, Blumenstein, \& Cook, 2013). Women have also reported the need to develop strategies to "do gender" or engage in gendered practices (Fenstermaker \& West, 2002; Ferree, 2010) within their families to maintain their families and persist in the doctoral program. In the Rockinson et al. (2018) study, women employed segmenting, so they could continue to shoulder the majority of care work (Hochschild, 2003). Some of the women reported getting up early or staying up late to attend to schoolwork, so it did not interfere with family life. Women reported taking measures and developing strategies so that the degree never really affected the family.

Consequently, researchers have documented that women are likely left feeling conflicted, shamed, and dissatisfied with the integration between the family and academic domains (Carter, Blumenstein, \& Cook, 2013). Therefore, it is also not surprising the results demonstrated that women had moderately lower ratings for academic-family balance than men. Women were not as satisfied with their academic-family interactions and functioning. The findings related to program type and gender have numerous implications.

\section{Implications}

Just as some workplaces have gone to great lengths to enable the integration of work and family, distance education programs boast of doing the same, promoting the flexible climate during the recruitment process (Hochschild, 1997; Kossek, Noe, \& DeMarr, 1999). Unfortunately, academic-family integration is rarely discussed beyond recruitment. As found in this research as well as previous studies (e.g., Rockinson-Szapkiw et al., 2017), distance education doctoral 
students may find academic and family boundaries blurry due to lack of physical boundaries between the two domains and institutions should put supports and programs in place to assist distance doctoral students in becoming aware of the potential for academic- family conflicts that can result from the lack of physical boundaries between the degree work and family domains. University faculty can educate distance students about the need to establish boundaries between academic and family domains, considering the students' preference for boundary setting and ensuring that segmenting is not merely a reactive attempt to navigate uncertain boundaries. For example, faculty may encourage students to ensure that they have a designated place in the home to study. Faculty can help students identify strategies to either segment or integrate, which may include learning cognitive strategies to resist the temptations to work on academic activities during family time or keeping separate calendars for family and academics.

The results of this study, do however, show that students vary in their preference to segment or integrate. Failure to discuss the topic of academic-family integration and student preferences can inhibit students' success, well-being, and ultimately degree completion in both types of programs. Therefore, university administrators, faculty, and staff should provide time within the doctoral curriculum (e.g., introduction course, doctoral orientation, family orientation) to discuss the type of program selected, the university and program culture, and personal preferences for integration and segmentation. Within introduction courses or orientations, doctoral students may be required to think about and create an academic-family integration plan, no matter if they are pursuing a distance of residential degree program. Moreover, like many institutions focus on family-friendly policies and supports on the recruitment and retention of faculty members (Springer et al., 2009), similar policies and supports for both residential and distance students should be developed. Policies and supports for residential and distance students may vary based on need but may include both childcare subsidies or maternity or paternity leaves of absence.

Additionally, as this study and previous research have demonstrated, assignments and discussions about academic-family integration should never be void of gender. As students, especially women, develop strategies to integrate the two domains, they need to address social and cultural norms and values within social contexts. Critical thinking and discussion with academic peers and doctoral faculty about policies, structures, and norms that perpetuate and reinforce traditionally gendered norms need to ensue. Students and faculty, in both residential and distance education programs, need to advocate for family-friendly policies (e.g., on-campus childcare, childcare stipends, family counseling, family-friendly grading policies) where they do not exist. While universities have made great strides in developing family-friendly policies for faculty and staff, consideration is needed for how these policies can extend to students to support retention and success.

Similarly, women and men need to discuss values and norms within their families, perhaps deconstructing structures within the home that privilege women as caretakers in the home and privilege men as academics, as this may affect doctoral program success and the level of satisfaction students experiences in academic-family integration. Even within same-sex couple relationships, one partner may take on the nurturing, caretaking role while the other takes on the academic role (Sweeney, Goldberg, \& Garcia, 2017). Intentional discussion about how the family can best support the doctoral student and ensure academic-family integration is needed. University staff, faculty, and administrators can facilitate discussions by offering family orientations or family counseling to students, either online or residentially (Abdous, 2019). 


\section{Limitations}

While this study provides many implications and interesting findings, limitations existed. The study was conducted in the United States, where gender norms associate women with family and men with academics (Reskin \& Bielby, 2005). Differences in academic-family integration may thus vary between genders in other cultures and countries. This study also focused on the discipline of education, and it is recognized that differences in academic-family integration may differ in other disciplines, especially where women have been historically underrepresented (e.g., STEM) (Byars-Winston \& Rogers, 2018). The study focused solely on integrating the academic and family domains. Many distance education doctoral students are employed full time. Therefore, work may be another variable that needs to be considered in future research.

Moreover, the findings only provide information about how students perceived their academic-family integration and do not reflect actual practice. Moreover, results do not account for students who chose not to participate, and responses were made only by students who identified as cisgender. This subjected the study to unit nonresponse and the issue of non-ignorable nonresponse. While item nonresponse was not a problem in this study; the problem of unit nonresponse needs to be noted as a limitation when applying and making inferences based on part one of this study (King, Honaker, Joseph, \& Shever, 1998). Statistical controls were not used to address the issue of non-ignorable nonresponse; therefore, findings should be applied with caution and only to the sample or populations that reflect the sample.

\section{Conclusion and Recommendation for Future Research}

While research has been published on work-family integration and policy within higher education (Wolf-Wendel \& Ward, 2014), little research has considered doctoral students' academic-family integration, which often sets the stage for their future work-family integration (Lester, 2013). This research thus adds to the academic-family integration literature, which is in a neophyte stage, by demonstrating that differences exist in how doctoral students integrate the academic and family domains based on program type and gender. The research also provides an impetus for a future study demonstrating a need to understand better the personal preferences of doctoral students and the types of programs that offer the best fit. Predictors of maximized academic-family satisfaction and functioning need to be explored. Programs need to be developed to address academic-family integration and their efficacy needs to be tested. 


\section{References}

Abdous, M. (2019). Well begun is half done: Using online orientation to foster online students' academic self-efficacy. Online Learning Journal, 23(3), 161-187. doi:10.24059/olj.v23i3.1437

Allen, I. E., \& Seaman, J. (2017). Digital learning compass: Distance education enrollment report 2017. Babson Survey Research Group.

Ashforth, B. E., Kreiner, G. E., \& Fugate, M. (2000). All in a day's work: Boundaries and micro role transitions. Academy of Management Review, 25(3), 472-491. doi:10.2307/259305

Athens, W. (2018). Perceptions of the persistent: Engagement and learning community in underrepresented populations. Online Learning Journal, 22(2), 27-57. doi:10.24059/olj.v22i2.1368

Bandura, A. (1986). Social foundations of thought and action: A social cognitive theory. Prentice-Hall.

Bergen, G., \& Bergen, M. B. (1978). Quality of marriage of university students in relation to sources of financial support and demographic characteristics. The Family Coordinator, 27(3), 245-250. doi:10.2307/582586

Berry, G. R., \& Hughes, H. (2020). Integrating work-life balance with 24/7 information and communication technologies: The experiences of adult students with online learning. American Journal of Distance Education, 34(2), 91-105. doi:10.1080/08923647.2020.1701301

Breitenbach, E. K., Bernstein, J., Ayars, C., \& Konecny, L. (2019). The influence of family on doctoral student success. International Journal of Doctoral Studies, 14, 761-782. doi: $10.28945 / 4450$

Brown, L., \& Watson, P. (2010). Understanding the experiences of female doctoral students. Journal of Further and Higher Education, 34(3), 385-404. doi:10.1080/0309877x.2010.484056

Brue, K. L. (2019). Work-life balance for women in STEM leadership. Journal of Leadership Education, 18(2). doi:10.12806/V18/R3

Brus, C. (2006). Seeking balance in graduate school: A realistic expectation or a dangerous dilemma? New Directions for Student Services, (115), 31-45. doi:10.1002/ss.214

Byars-Winston, A., \& Rogers, J. G. (2018). Testing intersectionality of race/ethnicity and gender in a social-cognitive career theory model with science identity. Journal of Counseling Psychology, 66(1), 30-44. doi:10.1037/cou0000309

Clark, S. C. (2000). Work/family border theory: A new theory of work/family balance. Human Relations, 53(6), 747-770. doi:10.1177/0018726700536001

Clark, S. C. (2002). Communicating across the work/home border. Community Work-Family, 5(1), 23-48. doi:10.1080/13668800020006802

Correll, S. J. (2001). Gender and the career choice process: The role of biased self-assessments. American Journal of Sociology, 106(6), 1691-1730. doi:10.1086/321299

Gajendran, R. S., \& Harrison, D. A. (2007). The good, the bad, and the unknown about 
telecommuting: Meta-analysis of psychological mediators and individual consequences. Journal of Applied Psychology, 92(6),1524-41. doi:10.1037/0021-9010.92.6.1524

Greenhaus, J. H., \& Powell, G. N. (2006). When work and family are allies: A theory of workfamily enrichment. Academy of Management Review, 31, 72-92.

doi:10.1016/j.jvb.2005.02.002.

Haynes, C., Bulosan, M., Citty, J., Grant-Harris, M., Hudson, J., \& Koro-Ljungberg, M. (2012). My world is not my doctoral program... or is it? Female students' perceptions of wellbeing. International Journal of Doctoral Studies, 7(1), 1-17. doi:10.28945/1555

Hollenshead, C. S., Sullivan, B., Smith, G. C., August, L., \& Hamilton, S. (2005). Work/family policies in higher education: Survey data and case studies in policy implementation. New Directions for Higher Education, 130, 41-65. doi:10.1002/he.178

Holley, K. A., \& Gardner, S. (2012). Navigating the pipeline: How socio-cultural influences impact first-generation doctoral students. Journal of Diversity in Higher Education, 5(2), 112-121. doi:10.1037/a0026840

Hyun, J. K., Quinn, B. C., Madon, T., \& Lustig, S. (2006). Graduate student mental health: Needs assessment and utilization of counseling services. Journal of College Student Development, 47(3), 247-266. doi:10.1353/csd.2006.0030

Jaggars, S., Edgecombe, N., \& Stacey, G. (2013). What we know about online course outcomes. Community College Research Center.

Jairam, D., \& Kahl, D. H. (2012). Navigating the doctoral experience: The role of social support in successful degree completion. International Journal of Doctoral Studies, 7, 311-329. doi: $10.28945 / 1700$

Kauffman, H. (2015). A review of predictive factors of student success in and satisfaction with online learning. Research in Learning Technology, 23, 1-13. doi:10.3402/rlt.v23.26507

King, G., Honaker, J., Joseph, A., \& Sheve, K. (1998). Listwise deletion is evil: What to do about missing data in political science. Department of Government Working Paper, Harvard University.

Kossek, E. E., \& Lautsch, B. A. (2012). Work-family boundary management styles in organizations: A cross-level model. Organizational Psychology Review, 2, 152-171. doi: $10.1177 / 2041386611436264$

Kowalski, K. B., \& Swanson, J. A. (2011). Managing telecommuters' work-family boundaries. Proceedings for The Northeast Decision Sciences Institute (NEDSI), 1269-1273.

Kreiner, G. E. (2006). Consequences of work-home segmentation or integration: A personenvironment fit perspective. Journal of Organizational Behavior, 27(4), 485-507. doi:10.1002/job.386

Kreiner, G. E., Hollensbe, E. C., \& Sheep, M. L. (2006). On the edge of identity: Boundary dynamics at the interface of individual and organizational identities. Human Relations, 59, 1315-1341. doi:10.1177/0018726706071525 
Kramarae, C. (2003). Gender equity online, when there is no door to knock on. In M. G. Moore \& W. G. Anderson (Eds.), Handbook of distance education (pp. 261-272). Lawrence Erlbaum Associates.

Kulp, A. M. (2016). The effects of parenthood during graduate school on $\mathrm{PhD}$ recipients' paths to the professoriate: A focus on motherhood. New Directions for Higher Education, 20(176), 81-95. doi:10.1002/he.20211

Kulp, A. M. (2019). Parenting on the path to the professoriate: A focus on graduate student mothers. Research in Higher Education, 61(3), 1-22. doi:10.1007/s11162-019-09561z

Kuperberg, A. (2009). Motherhood and graduate education: 1970-2000. Population Research and Policy Review, 28(4), 473-504. doi:10.1007/s11113-008-9108-3

Lent, R. W., Brown, S. D., \& Hackett, G. (1994). Toward a unifying social cognitive theory of career and academic interest, choice, and performance. Journal of Vocational Behavior, 45(1), 79-122. doi:10.1006/jvbe.1994.1027

Lester, J. (2013). Work-life balance and cultural change: A narrative of eligibility. Review of Higher Education, 36(4), 463-488. doi:10.1353/rhe.2013.0037

Lynch, K. D. (2008). Gender roles and the American academe: A case study of graduate student mothers. Gender and Education, 20(6), 585-605. doi:10.1080/09540250802213099

Madden, M. E. (2016). Planning for distance learning: Issues and strategies. Journal of Behavioral and Applied Management, 4(3), 256-286.

Martinez, E., Ordu, C., Della Sala, M., \& McFarlane, A. (2013). Striving to obtain a schoolwork-life balance: The full-time doctoral student. International Journal of Doctoral Studies, 8, 39-59. doi:10.28945/1765

Mason, M. A., Goulden, M., \& Frasch, K. (2009). Why graduate students reject the fast track. Academe Online, 95(1).

Methot, J. R., \& LePine, J. A. (2016). Too close for comfort? Investigating the nature and functioning of work and non-work role segmentation preferences. Journal of Business and Psychology, 31(1), 103-123. doi:10.1007/s10869-015-9402-0

Mirick, R. G., \& Wladkowski, S. (2020). Women's experiences with parenting during doctoral education: Impact on career trajectory. International Journal of Doctoral Studies, 15, 89109. doi:10.28945/4484

National Center for Education Statistics. (2020). The condition of education 2020. https://nces.ed.gov/programs/coe/indicator_chb.asp

National Science Foundation, National Center for Science and Engineering Statistics. (2018). Doctorate recipients from U.S. universities: 2016. Special report NSF 18-304. https://www. nsf.gov/statistics/2018/nsf18304/

National Science Foundation, National Center for Science and Engineering Statistics. (2019). Survey of earned doctorates. https://www.nsf.gov/statistics/srvydoctorates/\#tabs-2

Nippert-Eng, C. E. (1996). Home and work. University of Chicago Press. 
Offerman, M. (2011). Profile of the non-traditional doctoral degree student. New Directions for Adult and Continuing Education, 2011(129), 21-30. doi:10.1002/ace.39

Powell, G. N., \& Greenhaus, J. H. (2010). Sex, gender, and the work-to-family interface: Exploring negative and positive interdependencies. Academy of Management Journal, 53(3), 513-534. doi:10.5465/amj.2010.51468647

Reskin, B. F., \& Bielby, D. D. (2005). A sociological perspective on gender and career outcomes. The Journal of Economic Perspectives, 19(1), 71-86. doi:10.1257/0895330053148010

Rockinson-Szapkiw, A. J. (2019). Toward understanding factors salient to doctoral students' persistence: The development and preliminary validation of the Academic-Family Integration Inventory. International Journal of Doctoral Studies, 14, 237-258. doi:10.28945/4248

Rockinson-Szapkiw, A. J., Holmes, J., \& Stephen, J. S. (2019). Identifying significant personal and program factors that predict online EdD students' program integration. Online Learning Journal, 23(4), 313-335. doi:10.24059/olj.v23i4.1579

Rockinson-Szapkiw, A. J., Sosin, L. S., \& Spaulding, L. (2018). Does family matter? A phenomenological inquiry exploring the lived experiences of women persisting in distance education, professional doctoral programs. International Journal of Doctoral Studies, 13, 497-515. doi:10.28945/4157

Rockinson-Szapkiw, A. J., Spaulding, L. S., \& Lunde, R. M. (2017). Women in distance doctoral programs: How they negotiate their identities as mothers, professionals, and academics in order to persist. International Journal of Doctoral Studies, 12, 49-71. doi:10.28945/3671

Rockinson-Szapkiw, A. J., Spaulding, L. S., \& Spaulding, M. T. (2016). Integration and institutional factors that predict online, doctoral persistence. Internet and Higher Education, 31, 101-112. doi:10.1016/j.iheduc.2016.07.003

Rockinson-Szapkiw, A. J., Spaulding, L. S., Swezey, J. A., \& Wicks, C. (2014). Poverty and persistence: A model for understanding individuals' pursuit and persistence in a doctor of education program. International Journal of Doctoral Studies, 9, 181-190. doi: $10.28945 / 2049$

Sallee, M. W. (2013). Gender norms and institutional culture: The family-friendly versus the father-friendly university. Journal of Higher Education, 84(3), 363-396. doi:10.1080/00221546.2013.11777293

Sallee, M. W. (2016). Ideal for whom? A cultural analysis of ideal worker norms in higher education and student affairs graduate programs. New Directions in Higher Education, 20(16), 53-67. doi:10.1002/he.20209

Schmidt, M., \& Hansson, E. (2018). Doctoral students' well-being: A literature review. International Journal of Qualitative Studies on Health and Well-being, 13(1), 1508171. doi:10.1080/17482631.2018.1508171

Springer, K. W., Parker, B. K., \& Leviten-Reid, C. (2008). Making space for graduate student parents: Practice and politics. Journal of Family Issues, 30(4), 435-457. doi: $10.1177 / 0192513$ X08329293 
Stimpson, R. L., \& Filer, K. L. (2011). Female graduate students' work-life balance and the student affairs professional. In P. A. Pasque \& S. E. Nicholson (Eds.), Empowering women in higher education and student affairs: Theory, research, narratives, and practice from feminist perspectives (pp. 69-84). Stylus.

Sweeney, K. K., Goldberg, A. E., \& Garcia, R. L. (2017). Not a "mom thing": Predictors of gatekeeping in same-sex and heterosexual parent families. Journal of Family Psychology, 31(5), 521-531. doi:10.1037/fam0000261

Tabachnick, B. G., \& Fidell, L. S. (2007). Using multivariate statistics. Pearson/Allyn \& Bacon.

Tompkins, K. A., Brecht, K., Tucker, B., Neander, L. L., \& Swift, J. K. (2016). Who matters most? The contribution of faculty, student-peers, and outside support in predicting graduate student satisfaction. Training and Education in Professional Psychology, 10(2), 102-108. doi:10.1037/tep0000115

West, L. C. (2014). Communicating needs and nurturing familial relationships. In. A. J. Rockinson-Szapkiw \& L. S. Spaulding (Eds.), Navigating the doctoral journey: A handbook of strategies for success (pp. 19-30). Rowman \& Littlefield.

Williams, R. E. (1977). The perception of the impact of a doctoral program upon the marriage relationships of doctoral students at the University of Northern Colorado [Doctoral dissertation, University of Northern Colorado]. Dissertation Abstracts International, 38, 132.

Wolf-Wendel, L. E., \& Ward, K. (2014). Academic mothers: Exploring disciplinary perspectives. Innovative Higher Education, 40(1), 19-35. doi:10.1007/s10755-014-92934

Wu. B. H. (2018). The role of career optimism and perceived barriers in college students' academic persistence: A social cognitive career theory approach. [Doctoral dissertation, University of Southern Mississippi]. University of Southern Mississippi Digital Archive. https://aquila.usm.edu/dissertations/1548/ 